\title{
Los inicios de la reforma católica en la diócesis de Cádiz
}

\author{
Arturo Morgado García *
}

No permaneció España al margen de ese proceso de recristianización de las masas que supuso la Reforma católica, de la cual encontramos algunos preludios, como es bien sabido, durante el reinado de los Reyes Católicos, aunque hasta la segunda mitad del siglo XVI no podemos hablar de una acción continua al respecto. La ya amplia bibliografía existente sobre la cuestión ${ }^{1}$ nos permite descubrir cómo los grandes ejes de actuación fueron muy similares en toda la geografía española: convocatoria de sínodos, creación de seminarios conciliares, enfrentamientos entre obispos y cabildos por recuperar aquéllos sus prerrogativas perdidas, establecimiento de nuevos conventos y surgimiento de nuevas congregaciones religiosas, implantación de una clausura más estricta a las monjas, realización de visitas pastorales, intentos de erradicación de los abusos existentes en el interior del estamento clerical, especialmente el concubinato y el absentismo... El objetivo de este trabajo es el análisis de este proceso en el marco concreto de la diócesis de Cádiz, planteando de paso la situación del estamento eclesiástico de la misma y de la vida espiritual de los fieles a lo largo de la segunda mitad del siglo XVI.

* Universidad de Cádiz

Entre otros trabajos, y sin ánimo de ser exhautivos, podemos señalar BADA, J., Situació religiosa de Barcelona en el segle XVI (Barlelona 1970); BILINKOFF, J., The Avila of Saint Theresa. Religious Reform in a sixteenth century city (Ithaca U.P. 1986); CRUz, A.J., y PERRY, M.E., Culture and Control in Counter Reformation Spain (Minneapolis 1992); CHAISTIAN, W.J., Religiosidad local en la España de Felipe /I (Madrid 1991); CÁRCEL ORTI, V.. Historia de la Iglesia en Valencia, vol. 1 (Valencia 1986); Dedieu, J.P., "Christianisation en Nouvelle Castille. Catéchisme, communion et confirmation dans l'archevêché de Toledo 1540-1650", Mélanges de la Casa de Velázquez. XV, 1979; Kamen, H., The Phoenix and the Flame. Catalonia and the Counter Reformation (New Haven 1993); NALLE, S.T., God in La Mancha. Religious Reform and the People of Cuenca 1500 1650 (Baltimore 1992), Santos Diez, J.L., Política conciliar postridentina en España (Roma 1963); Tellechea ldigoras, J., El obispo ideal en el siglo de la Reforma (Roma 1969); VV.AA, Historia de la Iglesia en España, vols. III-1 y III-2. Madrid 1979; WRIGHT, A.D., Catholicism and Spanish Society under the Reign of Philip II and Philip III (1991), etc 


\section{LAS ESTRUCTURAS ECLESIÁSTICAS}

El 21 de agosto de $1263^{2}$ el papa Urbano IV enviaba a Alfonso X de Castilla una bula por medio de la cual se le concedía la restauración del obispado asidonense y el traslado de su capitalidad a Cádiz, concediendo facultad al obispo abulense Don Domingo Suárez para realizar dicha translación, nombrando éste a su vez al religioso franciscano Fray Juan Martínez como primer titular de la sede gaditana. Habría de hacer frente a la oposición del arzobispado de Sevilla don Remondo, que en 1261 había organizado la administración de dicha archidiócesis creando cinco arcedianatos con sede en Sevilla, Écija, Cádiz, Niebla y Reina, por lo que la primera tarea del nuevo prelado habría de ser el llegar a un entendimiento con la Iglesia hispalense: de este modo, en 1265 se firmaba un acuerdo por el que se fijaba como línea divisoria entre ambas sedes el curso del río Guadalete hasta su desembocadura en el Atlántico, y, dado que este compromiso no prosperó, el 23 de noviembre de 1267 Alfonso $X$ confirmaba en Jerez de la Frontera una nueva avenencia signada por el arzobispo, deán y cabildo de Sevilla y el obispo gaditano según la cual la diócesis gadicense comprendería Cádiz, la Isla de León y los territorios allende el Guadalete hasta donde entraba el Guadiaro en el mar, salvadas algunas excepciones.

Se trataba no obstante de límites meramente teóricos que no se hicieron plenamente efectivos hasta que no avanzó el proceso reconquistador: en 1292 las tropas castellanas tomaban Tarifa, lo que suponía la consolidación del dominio de Medina Sidonia, Alcalá de los Gazules y Vejer, en 1344 y definitivamente en 1379 Algeciras, en 1431 Jimena de la Frontera y Castellar, en 1462 Gibraltar, a la vez que surgían nuevas poblaciones cuando en 1493 los Reyes Católicos fundaban Puerto Real y en 1503 se iniciaba la existencia de la villa de Paterna de Ribera.

A finales del siglo xv el obispado de Cádiz había alcanzado sus límites definitivos: una diócesis pequeña, de unos 3.800 kilómetros cuadrados de extensión, y con una baja densidad demográfica ${ }^{3}$. Ello provocaría que durante el siglo XVI fuese, atendiendo al volumen anual de sus rentas, una

\footnotetext{
2 Sobre la creación de la diócesis de Cádiz, cfr. MANSILLA, D. "Creación de los obispados de Cádiz y Algeciras», Hispania Sacra, 10, 1957, y SánChez Herrero, J., Cádiz. La ciudad medieval y cristiana, 2 edición. Córdoba 1986, págs. 223 y ss.

3 En 1534 la población se elevaba (excluyendo a Gibraltar) a un total de 5.065 vecinos (Dominguez OAtiz, A., "La población del reino de Sevilla en 1534", Cuadernos de Historia. Anexos de la Revista Hispania, VII, 1977), que serían 8112 en 1591 (GonzÁLEZ, T., Censo de población de las provincias y partidos de la corona de Castilla en el siglo XVI. Madrid 1829, pág. 84).
} 
de las más débiles económicamente de toda la corona castellana. En 1533 el obispado valía 8500 ducados, si bien a lo largo del siglo XVI esta situación experimentaría una cierta mejora, ya que en 1577 las rentas de los prelados gaditanos alcanzaba los 12.000 ducados y en 1597 los $15.000^{4}$.

No contamos con datos anteriores, pero en 1605 (cuadro 1) los ingresos totales de la diócesis de Cádiz se elevaban a un total de 21.444.564 maravedís $(630.722,16$ reales de vellón), existiendo, como no podía ser menos, grandes desigualdades: el $37,6 \%$ de esta suma era percibida por el obispo y el cabildo catedralicio, el 33,5 por las fábricas parroquiales, beneficiados y distintos sirvientes de las iglesias, el 7,7 portonces, distintos conventos de religiosos y monjas existentes por aquel capellanías, y el 9,5 por los señores por las cofradías, el 10,6 por las capellanias, yenas beneficiadas por la laicos o instituciones eclesiásticas a saber: los duques de Arcos, Alcalá y Medina Sidonia, los condes de Castellar, la Universidad de Beneficiados de Jerez de la Frontera y la Capilla Real de Granada; y el convento de cartujos de Jerez de la Frontera en función de las rentas proporcionadas por los pastos de su propiedad radicados en el obispado gadicense.

Sin lugar a dudas, el diezmo era la principal fuente de ingresos de la Iglesia gaditana: ese mismo año de 1605 el 70,6 \% de los mismos procedía del producto decimal, en tanto que los bienes inmuebles y los censos garantizaban el 24,3, y las primacias y obvenciones tan sólo el $5 \%$. Solamente las cofradías, las capellanías y los convento en Cádiz, que percibía Colegio de Santiago de la Compañía de Jesús la diócesis) dependían susla veintena de las rentas de fábrica de toda la o de los censos impuestos a su favor. Pero el diez cabildo catedralicio ${ }^{6}$, el 82,1 de los de la obispos $^{5}$, el 95,9 de los del cabildo catedr

La misma Cádiz solamente podía contar con 671 y 612 vecinos respectivamente (BERNAL, A.M., La misma Cádiz solamente garcí BAQUERO, A., "Sevilla de los gremios a la industrialización", COLLANTES DE TERAN, A. , Y GARCial, 5-6, 1978, pág. 23).

Estudios de historia social, $5-6$, cit., pág. 288

4 SÁNCHez HeRrero,

5 Las rentas totales ascendieron de Sevilla, 15.000 arrendamiento de la maravedises, 24.000 juro sobre el almo huerta de San Ambrosio en Vejer, 160 prodo de las tierras arrancadas a un tal Dionisio Suárez de en Jerez de la Frontera, 33.000 producio de Cádiz, Toledo, 37.400 procedentes de 50 ca

Libro de subsidios de 1596-1623). de la Pitancería, 37.400 por 50 carneros recogidos en Jerez (lbidem) 
CUADRO 1. RENTAS DE LA DIÓCESIS DE CÁDIZ (1605)

\begin{tabular}{|c|c|c|c|c|c|c|}
\hline & 1 & 2 & 3 & 4 & 5 & 6 \\
\hline Cádiz & 8.063 .901 & 1.242 .220 & 588.998 & - & 626.612 & 192.980 \\
\hline Alcalá G. & - & 654.214 & 143.000 & - & 158.424 & 449.370 \\
\hline Castellar & - & 44.876 & - & - & - & 17.438 \\
\hline Conil & - & 308.722 & - & - & 47.732 & - \\
\hline Chiclana & - & 370.436 & - & 90.000 & 138.900 & - \\
\hline Gibraltar & - & 762.333 & 262.500 & 15.367 & 402.142 & - \\
\hline Jerez F. & - & 7.836 & - & - & - & 150.000 \\
\hline $\begin{array}{l}\text { Jimena } \\
\text { Medina }\end{array}$ & - & 578.430 & 20.322 & 10.517 & 90.880 & - \\
\hline Sidonia & - & 1.177 .314 & 344.500 & - & 252.366 & 1.060 .814 \\
\hline Paterna & - & 107.666 & - & - & 8.000 & - \\
\hline Puerto Real & - & 235.602 & - & 6.000 & 55.000 & 173.602 \\
\hline Tarifa & - & 648.580 & 137.168 & 57.581 & 242.198 & - \\
\hline Vejer & - & 1.064 .971 & 163.311 & - & 271.741 & - \\
\hline TOTAL & 8.063 .901 & 7.203 .200 & 1.659 .799 & 179.465 & 2.293 .995 & 2.044 .204 \\
\hline
\end{tabular}

1. Obispo y cabildo.

2. Rentas de las fábricas y salarios de curas y beneficiados.

3. Conventos.

4. Cofradías.

5. Capellanias.

6. Otros beneficiarios (diezmos percibidos por los duques de Arcos, Alcalá y Medina Sidonia, los condes de Castellar, la Universidad de Beneficiados de Jerez de la Frontera, la Capilla Real de Granada y el convento de cartujos de Jerez). Fuente: Archivo Catredalicio de Cádiz, Subsidios, libro de 1596-1623, cifras en maravedises.

Iglesia de Santa Cruz, la catedral de la urbe gaditana ${ }^{7}$ y el 78,1 de los de fábricas y sirvientes de las iglesias del obispado.

Se conoce bien el mecanismo administrativo de percepción del diezmo en la diócesis durante este período ${ }^{8}$, pero lo que más nos interesa sub-

7 Contamos con cierta información acerca de su situación económica a fines del siglo xvı. En 1599-1600 sus ingresos ascendieron a $2.993 .895 \mathrm{mrs}$., de los cuales 1.579 .485 correspondían al producto decimal del que la fábrica era beneficiario, 79.135 a derechos de entierro y el resto a 99 censos pagados fundamentalmente por plebeyos residentes en Cádiz, Chiclana. Medina Sidonia, Jerez de la Frontera y el Puerto de Santa María. Muchos de estos tributos no fueron pagados por los deudores, ya que las propiedades sobre las cuales estaban impuestos los mismos habian sido destruidas tras el asalto inglés de 1596. La situación económica de la fábrica debió ser tan precaria que en 1597 el prelado Maximiliano de Austria le concedía un donativo de $220.098 \mathrm{mrs}$. (ACC, Sección 3, serie 1, libro de cuentas de fábrica de 1598-1623).

a Vid. Traverso RuIz, F. Riqueza y producción agraria en Cádiz durante los siglos xVI y XVII. Cádiz 1987. 
rayar es el hecho de que sus grandes beneficiarios serán los grupos más privilegiados del estamento clerical: en 1605, y si hacemos exclusión de las tercias reales y del excusado recaudados por la corona, el 19,6 del mismo era percibido por el prelado y el 30,4 por el cabildo catedralicio gaditano, el 11,3 por los señores jurisdiccionales existente en la diócesis ${ }^{9}$, el 1,7 por el colegio de la Compañía de Jesús de Cádiz y la capilla real de Granada (que se beneficiaba de parte del diezmo recogido en la villa de Puerto Real), el 17,2 por los beneficios simplo, y tan sólo el 19,4 ibas presentes en las distintas localidades del obispado, yún caso los encara parar a las fábricas de las iglesias, sin quel del producto decimal.

Tras el obispo, la institución eclesiástica con mayor prestigio y dignidad era el cabildo catedralicio. Desde la bula promulgada por el papa Alejandro VI en 1502, estaba formado por seis dignidades (deán, arcedianos de Cádiz y Medina, tesorero, chantre y maestrescuela), dos canonjias de oficio, ocho canojías simples (una de ellas fue aplicada al Santo Oficio de la Inquisición en 1568), cuatro raciones y och, la provisión de estas prebendas correspondía al obispo, el papa naturales de la urbe gaditana ${ }^{11}$ y en 1502 el papa Alejandro VI concedía al capítulo catedralicio la provisión de todas las medias raciones que quedaran vacantes en cualquier tiempo y modo en que se produjere la misma ${ }^{12}$. Pero el modre de provisión de las prebendas produjo numerosos enfrentamien vacantes en el cabildo y los capitulares por el nombramiento de los cargos vacantrol de un cuerpo que en el pasado se había caracterizado por medio de garantizar su autonomía frente a cualquier injerencia externa. La urbe gaditana y la Santa Sede serían también partes interesadas en estos conflictos.

Los mismos, de hecho, fueron muy frecuentes en la segunda mitad del siglo XVI: en 1583 Bartolomé Lozano de Quirós exponía se le debía

- El duque de Arcos, el conde de Castellar, el duque de Medina Sidonia y el duque de

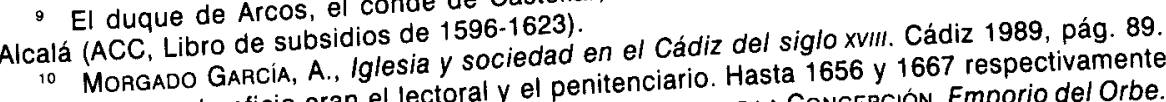
Los canónigos de oficio eran el lectoral y el penitenciario. Hasta 1656 y no se crearon las canonjías doctoral y magistra y 558 )

Cádiz llustrada. Amsterdam 1690, pa opuso a esta gracia, si bien el Consejo Real de Castilla El prelado Garcia de Harons del cabildo municipal gaditano (MORGado GaRcía, A., op. cit., pág. 91).

${ }_{12}$ Ibidem, pág. 92. 
CUADRO 1. RENTAS DE LA DIÓCESIS DE CÁDIZ (1605)

\begin{tabular}{|c|c|c|c|c|c|c|}
\hline & 1 & 2 & 3 & 4 & 5 & 6 \\
\hline Cádiz & 8.063 .901 & 1.242 .220 & 588.998 & - & 626.612 & 192.980 \\
\hline Alcalá G. & - & 654.214 & 143.000 & - & 158.424 & 449.370 \\
\hline Castellar & - & 44.876 & - & - & - & 17.438 \\
\hline Conil & - & 308.722 & - & - & 47.732 & - \\
\hline Chiclana & - & 370.436 & - & 90.000 & 138.900 & - \\
\hline Gibraltar & - & 762.333 & 262.500 & 15.367 & 402.142 & - \\
\hline Jerez F. & - & 7.836 & - & - & - & 150.000 \\
\hline Jimena & - & 578.430 & 20.322 & 10.517 & 90.880 & - \\
\hline \multicolumn{7}{|l|}{ Medina } \\
\hline Sidonia & - & 1.177 .314 & 344.500 & - & 252.366 & 1.060 .814 \\
\hline Paterna & - & 107.666 & - & - & 8.000 & - \\
\hline Puerto Real & - & 235.602 & - & 6.000 & 55.000 & 173.602 \\
\hline Tarifa & - & 648.580 & 137.168 & 57.581 & 242.198 & - \\
\hline Vejer & - & 1.064 .971 & 163.311 & - & 271.741 & - \\
\hline TOTAL & 8.063 .901 & 7.203 .200 & 1.659 .799 & 179.465 & 2.293 .995 & 2.044 .204 \\
\hline
\end{tabular}

1. Obispo y cabildo.

2. Rentas de las fábricas y salarios de curas y beneficiados.

3. Conventos.

4. Cofradías.

5. Capellanías.

6. Otros beneficiarios (diezmos percibidos por los duques de Arcos, Alcalá y Medina Sidonia, los condes de Castellar, la Universidad de Beneficiados de Jerez de la Frontera, la Capilla Real de Granada y el convento de cartujos de Jerez). Fuente: Archivo Catredalicio de Cádiz, Subsidios, libro de 1596-1623, cifras en maravedises.

Iglesia de Santa Cruz, la catedral de la urbe gaditana ${ }^{7}$ y el 78,1 de los de fábricas y sirvientes de las iglesias del obispado.

Se conoce bien el mecanismo administrativo de percepción del diezmo en la diócesis durante este período ${ }^{8}$, pero lo que más nos interesa sub-

7 Contamos con cierta información acerca de su situación económica a fines del siglo xvI. En 1599-1600 sus ingresos ascendieron a $2.993 .895 \mathrm{mrs}$, de los cuales 1.579 .485 correspondían al producto decimal del que la fábrica era beneficiario, 79.135 a derechos de entierro y el resto a 99 censos pagados fundamentalmente por plebeyos residentes en Cádiz, Chiclana, Medina Sidonia, Jerez de la Frontera y el Puerto de Santa María. Muchos de estos tributos no fueron pagados por los deudores, ya que las propiedades sobre las cuales estaban impuestos los mismos habían sido destruidas tras el asalto inglés de 1596. La situación económica de la fábrica debió ser tan precaria que en 1597 el prelado Maximiliano de Austria le concedía un donativo de $220.098 \mathrm{mrs}$. (ACC, Sección 3, serie 1, libro de cuentas de fábrica de 1598-1623).

8 VID. Thaverso RUIz, F. Riqueza y producción agraria en Cádiz durante los siglos XVI y XVII. Cádiz 1987. 
rayar es el hecho de que sus grandes beneficiarios serán los grupos más privilegiados del estamento clerical: en 1605, y si hacemos exclusión de las tercias reales y del excusado recaudados por la corona, el 19,6 del mismo era percibido por el prelado y el 30,4 por el cabildo catedralicio gaditano, el 11,3 por los señores jurisdiccionales existente en la diócesis ${ }^{9}$, el 1,7 por el colegio de la Compañía de Jesús de Cádiz y la capilla real de Granada (que se beneficiaba de parte del diezmo recogido en la villa de Puerto Real), el 17,2 por los beneficios simples y las prestameras presentes en las distintas localidades del obispado, y tan sólo el 19,4 iba a parar a las fábricas de las iglesias, sin que en ningún caso los encargados de la cura de almas se beneficiaran del producto decimal.

Tras el obispo, la institución eclesiástica con mayor prestigio y dignidad era el cabildo catedralicio. Desde la bula promulgada por el papa Alejandro VI en 1502, estaba formado por seis dignidades (deán, arcedianos de Cádiz y Medina, tesorero, chantre y maestrescuela), dos canonjías de oficio, ocho canojías simples (una de ellas fue aplicada al Santo Oficio de la Inquisición en 1568), cuatro raciones y ocho medias raciones ${ }^{10}$. Según la época del año en que quedaran vacantes, la provisión de estas prebendas correspondía al obispo, el papa o al cabildo catedralicio, si bien las raciones estaban reservadas a los naturales de la urbe gaditana ${ }^{11}$ y en 1502 el papa Alejandro Vl concedía al capítulo catedralicio la provisión de todas las medias raciones que quedaran vacantes en cualquier tiempo y modo en que se produjere la misma ${ }^{12}$. Pero el modo de provisión de las prebendas produjo numerosos enfrentamientos entre los prelados y los capitulares por el nombramiento de los cargos vacantes en el cabildo gaditano: si para los primeros ello suponía un mayor control de un cuerpo que en el pasado se había caracterizado por su rebeldía ante la autoridad episcopal, para los segundos era el único medio de garantizar su autonomía frente a cualquier injerencia externa. La urbe gaditana y la Santa Sede serían también partes interesadas en estos conflictos.

Los mismos, de hecho, fueron muy frecuentes en la segunda mitad del siglo XVI: en 1583 Bartolomé Lozano de Quirós exponía se le debía

9 El duque de Arcos, el conde de Castellar, el duque de Medina Sidonia y el duque de Alcalá (ACC, Libro de subsidios de 1596-1623).

- Morgado García, A., Iglesia y sociedad en el Cádiz del siglo xvil. Cádiz 1989, pág. 89. Los canónigos de oficio eran el lectoral y el penitenciario. Hasta 1656 y 1667 respectivamente no se crearon las canonjias doctoral y magistral (GERÓNIMO DE LA CONCEPCIÓN, Emporio del Orbe. Cádiz llustrada. Amsterdam 1690, págs. 555 y 558).

El prelado García de Haro se opuso a esta gracia, si bien el Consejo Real de Castilla reconocía en 1574 las pretensiones del cabildo municipal gaditano (MORGado García, A., op. cit., pág. 91).

${ }_{12}$ Ibidem, pág. 92. 
conceder la canonjía vacante por el fallecimiento de Pedro Ochoa Termineli en detrimento de Álvaro Arias, ya que las bulas papales presentadas por éste eran subrepticias ${ }^{13}$, acusación que volvió a pesar sobre el mencionado Álvaro Arias dos años más tarde cuando pretendió el canonicato vacante tras la muerte de Diego de Herrera, oponiéndose en esta ocasión el cabildo a sus pretensiones ${ }^{14}$. En 1588 la ciudad solicitaba que la ración vacante tras la muerte de Diego Romero fuese provista en la persona de Miguel Barreçueta, si bien el cabildo catedralicio, con la aquiescencia del prelado, se inclinaría por Ginés de Boluda ${ }^{15}$. Once años más tarde el obispo Maximiliano de Austria nombraba como racionero a su camarero Diego de Mena y Sanabria, lo que provocó las protestas del cabildo municipal por no ser el agraciado natural de la urbe gaditana ${ }^{16}$.

La vida cotidiana de los capitulares gaditanos estaba reglamentada por los estatutos promulgados en 1493 y 1589 , debiendo, según los mismos, asistir a los cabildos; cumplir con la residencia (lo que no impedía que muchas de las funciones litúrgicas se celebraran de un modo rutinario, como se refleja del hecho de que en 1598 y 1599 se exhortara a los capitulares a rezar las horas y funciones sacras con un poco más de devoción) ${ }^{17}$ y guardar en todo momento un comportamiento decente y honesto. Los estatutos de 1589 serían promulgados por una comisión formada por el prelado Antonio Zapata y Cisneros, el deán Rodrigo de Villavicencio y el canónigo Álvaro Arias, reglamentándose la celebración de los cabildos, el modo de comportarse en los mismos y de proceder a las votaciones, y la administración de los bienes y propiedades de la Iglesia de Santa Cruz ${ }^{18}$.

El poder económico de los capitulares gaditanos era impresionante, ya que amén de ser los mayores beneficiarios del producto decimal recogido en la diócesis, gozaban también de una serie de rentas derivadas de su asistencia a las funciones litúrgicas celebradas en la catedral, contando además con los bienes de su propiedad y las capellanías a su cargo. Según Agustín de Horozco, a finales del siglo Xvı la renta de los prebendados oscilaba entre 600 y 700 ducados anuales ${ }^{19}$, cifra que nos

13 ACC, Sección 1, serie 1, lib. 1, tols. 51v-52.

14 Ibidem, fol. $287 \mathrm{v}$.

15 Ibidem, lib. 2, fols. 47-51.

Ibidem, lib. 3, s.f.

Ibidem, lib. 3, s.f.

18 A (rchivo) D (iocesano) de C (ádiz), Erección de la Santa iglesia Catedral de Cádiz y estatutos del Cabildo de dicha Iglesia, «Estatutos modernos de los sres. Deán y Cabildo de la Santa Iglesia de Cádiz" (1589), fols. 57-70.

${ }^{19}$ Horozco, A. de, Historia de la ciudad de Cádiz. Cádiz 1845, pág 242. 
parece exagerada, pero lo cierto es que la situación económica de los capitulares debió ser bastante boyante, como prueba el testamento del racionero Pedro Díaz Zarco, fallecido en 1599, según el cuál era propietario de cuatro esclavos, tres casas, una huerta y 51 aranzadas de tierra en la localidad de Vejer, un censo de 100 ducados de principal y deudas a favor por un importe de 330 reales $^{20}$.

Muy distinta era la situación del bajo clero secular. Según las Constituciones Sinodales promulgadas en 1591 todos aquellos que desearan acceder al estamento eclesiástico debian ser hijos de legítimo matrimonio, estar bautizados y confirmados, contar con una mínima formación intelectual (en la práctica, saber leer, escribir y dominar los rudimentos de la lengua latina) y proporcionar una congrua anual de 12.000 maravedís, corriendo a cargo de los vicarios el realizar una información previa de vita, genere et moribus del candidato en la que se interrogara a una serie de testigos acerca de la honestidad y vocación del pretendiente ${ }^{21}$. No consta se exigiera limpieza de sangre, pero ya en 1596 encontramos declaraciones afirmativas en este sentido realizadas por los testigos interrogados $^{22}$.

Una serie de 31 expedientes fechados entre 1596 y 1599 nos muestran cómo el reclutamiento del estamento clerical se realizaba fundamentalmente en los territorios situados en el interior de la diócesis (siete pretendientes eran originarios de Alcalá de los Gazules, seis de Jimena, cuatro de Medina Sidonia, cinco de Tarifa y Vejer, tres de Chiclana) y cómo se trataba de hombres muy jóvenes, ya que cinco de ellos tenían entre doce y diecisiete años cuando solicitaron recibir la primera tonsura, única indicación con la que contamos acerca de su edad. Poco más sabemos de ellos: tan sólo que un tal Nicasio Cáceres era hijo 'del hombre más rico en dineros' de la localidad de Jimena ${ }^{23}$, aunque no sabemos si este dato podemos extrapolarlo a los restantes aspirantes a órdenes.

A la cabeza del bajo clero secular se encontraban los curas, cuyo número debía ser muy reducido, ya que en 1587 solamente existían 14 pilas en todo el obispado ${ }^{24}$. Su situación económica era en líneas generales bastante precaria, ya que sus únicos ingresos procedían del pro-

ADC, Varios, leg. 2971.

21 Morgado García, A., El clero gaditano a fines del Antiguo Régimen. Estudio de las órdenes sacerdotales (1700-1834). Cádiz 1989, pags. 108-109.

${ }_{22}$ ADC, Órdenes, leg. 1, expediente de Pedro de Morales (Alcalá 1596).

23 ADC, Órdenes, leg. 1.

24 Una en Puerto Real, Cádiz, Medina Sidonia, Vejer, La Barca, Jimena, Castellar, Alcalá, Paterna, Chiclana y Conil y dos en Tarifa (González, T., op. cit., pag. 227). 
ducto de las primicias y obvenciones, sin percibir parte alguna del producto decimal. Normalmente sólo existía una parroquia en cada localidad del obispado, y en algunas poblaciones incluso se dio una disminución numérica de las mismas, tal como sucedió en Tarifa ${ }^{25}$ y en Alcalá de los Gazules, en la cual Fadrique Enríquez de Ribera, primer marqués de Tarifa, obtenía en 1524 del papa Clemente VII la unión en una sola parroquia de las hasta entonces tres existentes en la villa ${ }^{26}$. El título 14 de las Constituciones Sinodales de 1591 está dedicado en su integridad a los curas, a los cuales se encarga la administración de los santos sacramentos, la celebración de la misa parroquial, la visita de los enfermos de la localidad, el procurar que los fieles enviaran a misa a sus hijos, criados y esclavos, el cuidado de las doncellas pobres, viudas, huérfanas, enfermos y ancianos, y la resolución de las disputas surgidas en el seno de la comunidad ${ }^{27}$.

Más privilegiada era la situación de los benefiados, los cuales, a diferencia de los curas, no tenían la obligación de dedicarse a la curae animarum ni de residir en la localidad donde radicaba su beneficio. Nos consta que a inicios del siglo xVII había un beneficio en la Isla de León, diez beneficios y las tres capellanías llamadas del Terzuelo en Alcalá de los Gazules, un beneficio en Castellar, uno en Conil, uno en Chiclana, cinco en Gibraltar, dos en el término de Jerez de la Frontera dependiente de la diócesis gadicense, cinco en Jimena, cinco en Medina Sidonia, uno en Paterna, uno en Puerto Real, cuatro beneficios y dos prestameras en Tarifa y siete beneficios y una prestamera en Vejer ${ }^{28}$, encontrándose los poseedores de los mismos en una situación económica bastante boyante al gozar de parte de las rentas derivadas del producto decimal. La provisión de dichos beneficios recaía en manos del papa cuando la vacante se producía en los ocho meses apostólicos y del obispo si quedaba libre en los cuatro meses ordinarios, aunque el beneficio del priorato de la Iglesia de San Sebastián de Puerto Real pertenecía al Real Patronato, y los diez beneficios simples existentes en Alcalá de los Gazules desde 1524 eran provistos por medio de oposición entre los naturales de dicha villa, teniendo sus poseedores la obligación de cantar las horas canónicas en el coro de la parroquia de dicha localidad y asistir a la procesión claustral celebrada los domingos y festivos ${ }^{29}$.

25 Gerónimo de la Concepción, op. cit., Amsterdam, pág. 529.

26 Ramos Romero, M. Historia de los pueblos de la provincia de Cádiz: Alcalá de los Gazules, Cádiz, s.a. pág. 311.

27 Morgado García, A. El clero, págs. 37-38.

28 ACC, Libro de Subsidios de 1596-1623, datos de 1605.

29 Ramos Romero, M., op. cit., págs. 261 y 311. 
En 1605 había un total de 280 capellanías en toda la diócesis: 47 en Cádiz, 18 en Alcalá de los Gazules, 4 en Castellar, 15 en Conil, 57 en Gibraltar, 11 en Jimena, 63 en Medina Sidonia, una en Paterna, 5 en Puerto Real, 27 en Tarifa y 32 en Vejer ${ }^{30}$. Muchas de ellas fueron fundadas con la finalidad de proporcionar a los retoños una cómoda existencia en el seno de la Iglesia, por lo que, a fin de evitar abusos, las Constituciones Sinodales disponian que los beneficiados tenían la obligación de residir en las iglesias donde radicara su beneficio, que nadie gozara de un beneficio con una carga superior a las 25 misas mensuales (con lo que se pretendía impedir la acumulación de beneficios en una sola persona y el incumplimiento de sus obligaciones que ello conllevaba) y que los capellanes cumplieran con todos los requisitos dispuestos en las fundaciones piadosas ${ }^{31}$, aunque la observancia de estas disposiciones debió dejar bastante que desear.

Las autoridades diocesanas pretendían controlar la moralidad del estamento eclesiástico y el cumplimiento de sus obligaciones por medio de las Visitas pastorales, realizadas por el obispo o por algún agente expresamente nombrado por el prelado, debiendo inspeccionar el estado de los templos y edificios sagrados, las posesiones de fábricas y capellanías, el cumplimiento de las obligaciones anejas al disfrute de las rentas de las mismas, la situación moral del clero, la administración de los sacramentos, la predicación al pueblo y el grado de observancia de los mandatos eclesiásticos por parte de los fieles ${ }^{32}$.

En 1500 tan sólo existían en la diócesis los conventos de mercedarios calzados de Algeciras (fundado en la primera mitad del siglo $\mathrm{XIV}^{33}$ ), de franciscanos de Gibraltar (1490) ${ }^{34}$ y un tercero de la misma orden en Jimena (siglo Xv) ${ }^{35}$. La casi completa inexistencia de institutos monásticos se deberá a la situación de pobreza del obispado, incapaz de subvenir las necesidades de los monasterios, y al escaso interés mostrado por los obispos por mejorar la situación espiritual de sus feligreses (de hecho, durante gran parte del siglo XVI los prelados gaditanos ni siquiera residieron en su diócesis) ${ }^{36}$. Esta situación, no obstante, cambiará extraordi-

ACC, Libro de subsidios de 1596-1623, datos de 1605.

31 Morgado Garcia, A. El clero, pág. 39.

32 Ibidem, pag. 117.

33 Sánchez Herrero, J. Cádiz y su provincia, tomo II. Sevilla 1984, pág. 199.

34 Caldelas López, R. La parroquia de Gibraltar en San Roque. Cádiz 1976, pág. 27.

$35 \mathrm{~V}$.A pág. 104.

36 Sancho De Sopranis, $H$. «El convento de San Francisco de Cádiz. Notas y documentos para la historia de sus primeros treinta años", Archivo Iberoamericano, VII, 1947, pags. 311 . 312. 
nariamente a lo largo de esta centuria, ya que durante la misma se establecieron los dominicos, los mínimos y las franciscanas de Santa Clara en Alcalá de los Gazules ${ }^{37}$, los mínimos en Conil ${ }^{38}$, los agustinos en Chiclana ${ }^{39}$, los mercedarios, los hospitalarios de San Juan de Dios y las franciscanas de Santa Clara en Gibraltar ${ }^{40}$, los mínimos en Jimena ${ }^{41}$, los agustinos calzados, los franciscanos descalzos, los mínimos y las agustinas calzadas de San Cristóbal en Medina Sidonia ${ }^{42}$, los trinitarios calzados en Tarifa ${ }^{43}$, los mercedarios descalzos y las franciscanas concepcionistas en Vejer ${ }^{44}$ y los jesuitas, los franciscanos observantes, las franciscanas concepcionistas de Santa Maria y las agustinas descalzas de Nuestra Señora de la Candelaria en la urbe gaditana ${ }^{45}$.

Llama poderosamente la atención el hecho de que de una veintena de casas religiosas, la inmensa mayoría se estableciera en las tierras de la Campiña gaditana, que debía constituir por aquel entonces el centro de gravedad económico del obispado gadicense. En la inmensa mayoría de las ocasiones la iniciativa fundacional no partirá de las órdenes religiosas interesadas, sino de los prelados, los cabildos municipales, el cabildo catedralicio o los propios fieles, los cuales, animados por su devoción o por satisfacer unas determinadas necesidades espirituales, pondrán todos los medios a su alcance para permitir el surgimiento de estos nuevos institutos monásticos, cuya floración, en cualquier caso, no hace más que reflejar una tendencia generalizada en la España del siglo XVI.

Por su gran trascendencia, es obligatorio detenerse en las primeras incidencias del colegio de Santiago de la Compañía de Jesús. Sus orígenes se remontan a 1558, año en que los padres Diego López y Gregorio de Mata llegaron a la urbe gaditana a fin de solicitar la autorización episcopal para predicar en las almadrabas de Conil y Zahara. Dado que el obispo, en aquellos momentos Jerónimo Teodoli, se encontraba presente en el concilio de Trento, los jesuitas se vieron obligados a permanecer

37 Vid. Ramos Romero, A., op. cit., págs. 346, 355 y 362.

38 ANTÓN SOLÉ, P., "Cádiz, diócesis de», Diccionario de Historia Eclesiástica de España, volumen 1. Madrid 1972, pag. 304.

39 vv.AA. Los pueblos de la provincia de Cádiz. Chiclana de la Frontera. Cádiz 1982, pág. 47.

40 Caldelas lópez, R. op. cit. págs. 27, 30 y 31.

4 ANTÓn SOlÉ, P., op. cit, pág. 305.

42 Ramos Romero, M. Medina Sidonia. Arte, historia y urbanismo. Cádiz 1981, pág. 239 y Antón SOLÉ, P., op. cit., pág. 304.

43 Ya es citado en 1605 (ACC, Libro de subsidios de 1596-1623).

44 Morillo Crespo, A., Vejer de la Frontera y su comarca. Aportaciones a su historia (Cádiz 1974, pág. 419) y ACC, libro de subsidios de 1596-1623.

45 Gerónimo de LA CONCEPCIÓN, op. cit. 
algunos dias en la ciudad despertando gran entusiasmo con sus predicaciones, por lo que a partir de entonces el provincial de la orden enviaría anualmente algunos padres a la ciudad. En 1561 el cabildo municipal gaditano rogó a la Compañía se hiciera cargo de los estudios de Gramática, y cinco años más tarde los jesuitas tomaban posesión de la ermita de Santiago y de la casa aneja a la misma. En noviembre de 1568 se inauguraba la enseñanza de primeras letras y en mayo de 1569 las lecciones de latinidad, por cuyo ejercicio la Compañia pasó a percibir la veintena de las rentas de fábrica de todas las iglesias del obispado ${ }^{46}$. Para compensar al colegio de los daños sufridos tras el asalto inglés de 1596, al año siguiente el cabildo municipai concedía a los jesuitas las rentas de la pescadería de la urbe en calidad de limosna ${ }^{47}$.

\section{LA VIDA ESPIRITUAL}

Nos es desconocida en gran medida la situación espiritual de los fieles gaditanos del Quinientos. La escasez de documentación y el deterioro de la misma ha frenado las investigaciones, por lo que solamente pueden ofrecerse algunas pinceladas sueltas.

El número de iglesias experimentó un incremento a lo largo de este período como consecuencia de la modesta prosperidad económica que vive la diócesis durante el siglo xvi: sabemos que durante esta centuria se fundaron entre otras la iglesia del Rosario en Vejer ${ }^{48}$, la iglesia de San Mateo en Tarifa ${ }^{49}$, se renueva la iglesia de Nuestra Señora de la Misericordia en Jimena ${ }^{50}$ y se edifican en Medina Sidonia las iglesias de Santa María la Coronada y Santiago, y la ermita de Santa Ana ${ }^{51}$. En el mismo Cádiz existían por aquel entonces las iglesias y ermitas de Santa Catalina, Santiago, Santa María, San Sebastián, San Roque, Nuestra Señora del Rosario, Nuestra Señora de la Candelaria, la iglesia del Hospital de la Misericordia y la Real Capilla de Nuestra Señora del Pópulo, iniciada ésta en $1599^{52}$. Muchos de estos templos estaban situados en los arrabales

\footnotetext{
46 Antón Solé, P., El Colegio de la Compañia de Jesús de Cádiz. Fundación (1564-1569). Cádiz 1959.

47 Perea Guardeño, G., "Las órdenes religiosas en Cádiz a través de las actas capitulares. Estudio cronológico (1566 a 1609)", Hispania, IX, 1949, pág. 600ss

${ }_{48}$ Morillo Crespo, A., op. cit., pág. 415.

49 VV.AA, Los pueblos de la provincia de Cádiz. Tarifa. Cádiz 1984, pág. 118.

so VV.AA, Los pueblos de la provincia de Cádiz. Jimena de la Frontera. Cádiz 1984, pág. 99.

51 Ramos Romero, M., Medina Sidonia..., págs. 275, 279 y 303.

52 Sánchez Herrero, J., Cádiz.., págs. 234-238.
} 
de la urbe y con el tiempo albergarían entre sus muros a las distintas comunidades religiosas que se asentaron en la ciudad. La gaditana iglesia de Santa Cruz tenía el rango de catedral de la diócesis.

Las autoridades diocesanas se preocuparon porque en las iglesias reinara el orden y la compostura correspondientes durante la celebración de los divinos oficios, que ningún seglar pretendiera eminencia «de lugares ni asientos", que en las mismas no se celebraran negocios, tuvieran lugar danzas profanas, juegos de naipes ni representaciones teatrales de la Pasión de Jesucristo, que en sus paredes no se colgaran tapices representando afiguras obscenas y deshonestas, ni retratos y pinturas desnudas o de gentiles" ${ }^{53}$, y que los jueces seculares respetaran escrupulosamente el derecho de asilo de las mismas ${ }^{54}$.

Poco o nada sabemos de las cofradías, tan sólo que, atendiendo a la escasa información que obra en nuestro poder, su número debía ser bastante reducido. En la diócesis había a inicios del siglo XVII, a tenor de los libros de subsidios, un total de once, dos de ellas dedicadas al Santísimo Sacramento, una a las ánimas del Purgatorio, tres marianas y el resto con advocaciones de diversos santos ${ }^{55}$. Por lo que se refiere a Cádiz, ya a finales del siglo XVI algunas de ellas participaban en las procesiones de semana Santa, mencionando Agustín de Horozco un total de quince, sustentándose todas ellas de las limosnas y cuotas proporcionadas por los fieles ${ }^{56}$. Muchas debian dedicarse a funciones asistenciales, aunque las Constituciones Sinodales de 1591 disponían además que acompañaran a la cruz de parroquia en todas las procesiones que salieran de la misma, prohibiéndose al mismo tiempo la fundación de cofradía o hermandad alguna sin previa licencia episcopal ${ }^{57}$.

Muy precaria debía ser la organización de la beneficiencia. En Alcalá de los Gazules Bartolomé Sánchez y Catalina Aguayo habian fundado en 1514 el Hospital de la Misericordia ${ }^{58}$, existiendo en Medina Sidonia los hospitales del Amor de Dios (1544) y San Juan de Dios (1579) ${ }^{59}$. Cádiz solamente contaba con el Hospital de la Misericordia, ya existente en $1514^{60}$ en el cuál se curaban los heridos y enfermos de la ciudad y de

s3 Sínodo diocesano de Cádiz. Año de 1882, "Constituciones antiguas del obispado de Cádiz", tít. VI.

${ }^{54}$ lbidem, tit. XXVI.

${ }_{55}$ ACC, Libro de subsidios de 1596-1623, datos de 1605.

56 Horozco, A. de, op. cit., pág. 270.

57 "Constituciones antiguas...", tit. VIII.

58 Ramos Romero, M., Historia de los pueblos de la provincia de Cádiz. Alcalá de los Gazules, pág. 369.

59 Ramos Romero, M., Medina Sidonia..., págs. 276-277.

60 Sánchez Herrero, J., Cádiz..., pág. 293. 
las naves que atracaban en su puerto, basando su economía fundamental en las limosnas. A finales del siglo XVI se instalaron en el mismo cuatro hermanos de la orden de San Juan de Dios para cuidar a los pacientes y un capellán de dicho instituto para decir una misa ordinaria ${ }^{61}$. Gibraltar albergaba al hospital de San Juan de Dios ${ }^{62}$ y en Chiclana en 1532 la cofradia de San Martín se trasladaba a lo que luego sería el Hospital del Niño Jesús ${ }^{63}$. Pero esta red hospitalaria debia ser claramente insuficiente, denunciando el sínodo de 1591 cómo «en algunos lugares de nuestro obispado, donde no hay casa de pública hospitalidad, los enfermos pobres vecinos y otros forasteros padecen miserablemente, y se mueren por no haber quien los remedie", exhortando a los regimientos y a las personas acaudaladas hicieran cuanto estuviera en su mano para acabar dicha situación ${ }^{64}$.

Desconocemos las devociones existentes en el obispado durante este período. El sínodo de 1591 redujo el número de días festivos de la diócesis a 33 , en los cuales los fieles debian abstenerse de ejecutar trabajos serviles salvo en caso de urgente necesidad, exhortando a los curas a que amonestasen a los fieles a oír misa y los divinos oficios y guardaran los ayunos. La devoción mariana debía tener ya cierta importancia, puesto que se reconocia que estas festividades debian celebrarse "con particular demostración y devoción de los fieles» ${ }^{65}$. Nos consta la existencia en la urbe gaditana de una procesión realizada por ambos cabildos a la ermita de San Sebastián el día de su advocación por haber dicho santo librado a la ciudad de una epidemia de peste ${ }^{66}$, así como la celebración del Corpus, puesto que en 1585 el cabildo catedralicio exhortaba a que el mismo tuviera lugar con la mayor solemnidad en atención a ser "este lugar puerto de mar donde concurren tantas naciones extranjeras y algunas sospechas de Nuestra Santa Fe a quien se hace obligación de dar ejemplo" ${ }^{67}$. En ocasiones extraordinarias se celebraban rogativas: en 1583 se celebró una pidiendo el fin de la sequía ${ }^{68}$, en 1588 tuvieron lugar por el buen éxito de la Armada Invencible ${ }^{69}$ y por la sequía ${ }^{70}$, en 1589 , "por-

HOROzCo, A., de op. cit., pág. 269.

62 Caldelas lópez, R., op. cit., pág. 30.

63 VV.AA, Los pueblos de la provincia de Cádiz. Chiclana de la Frontera. Cádiz 1984, pág. 50.

64 "Constituciones antiguas", tit. VIII, pág. 5.

Ibidem, tit. Ill.

Sánchez Herrero, J., Cádiz..., pág. 291.

ACC, Sección 1, serie 1, lib. 1, fols. $283 \mathrm{v}-284$.

loidem, fols. 48 y $49-51$.

ACC, Sección 1, serie 1, lib. 2, fols. 74-v y 89v-90.

Ibidem, fols. 133-v y $190 \mathrm{v}$. 
que Nuestro Señor mire el remedio de las cosas de su Iglesia que tanta pesadumbre y molestia recibe de los herejes" ${ }^{71}$.

Sobre la vida sacramental apenas contamos con información, si bien las Constituciones sinodales de 1591, fieles a la revalorización de aquella pretendida por la Reforma católica, dedican una gran importancia a este punto. Por lo que se refiere al bautismo, se pretende conseguir que los padres hagan administrar este sacramento a sus hijos lo antes posible, disponiéndose que la recepción del mismo tenga lugar en un plazo máximo de ocho días después del nacimiento, ordenándose asimismo la confección de los libros correspondientes ${ }^{72}$. Apenas se le dedica importancia alguna a la confirmación, limitándose a exhortar a curas y vicarios amonestaran a los fieles para que sus hijos y criados recibieran la misma teniendo edad suficiente ${ }^{73}$. Mayor trascendencia, lógicamente, se le daba a la Eucaristia, hasta el punto de ordenarse a curas y vicarios fomentaran la fundación de cofradias del Santísimo Sacramento ${ }^{74}$. La penitencia también se encontraba en el centro de las autoridades diocesanas: se ordenaba a los curas interrogaran al recipendario acerca de los puntos fundamentales de la doctrina cristiana, se dispone que solamente se administre en los confesionarios, que los sacerdotes no pudiesen oír a mujeres en confesión sin haber cumplido al menos cuarenta años, que todos los que administraran este sacramento tuviesen licencia episcopal, que aquellos fieles con ocho años cumplidos se confesaran una vez al año por Pascua y se manifiesta una gran preocupación por aquellos que acudían a Berbería a comerciar y estaban uno, dos o tres años sin recibir los sacramentos ${ }^{75}$. Por lo que se refiere al matrimonio, se ordena a los curas que no administren este sacramento sin las previas amonestaciones, y se anula la validez de los esponsales contraídos sin que hubiera clérigo presente $^{76}$.

Pero, en líneas generales, la situación espiritual de los fieles no era muy halagüeña. Tengamos en cuenta la deficiente red parroquial de la diócesis, la tardía implantación de las órdenes religiosas en la misma y la pobreza de medios en general de la Iglesia gaditana, y llegaremos a la conclusión de que aún había mucho que hacer en el terreno de esa especie de “recristinianización" de las masas que pretendió llevar a cabo

\footnotetext{
lbidem, fol. 227.

"Constituciones antiguas", tit. IV, "Del sacramento del baptismo", Ibidem "Del sacramento a la confirmación».

Ibidem, "Del sacramento a la eucaristia».

Ibidem, "Del sacramento a la penitencia».

lbidem, "Del sacramento del matrimonio".
} 
la Reforma Católica. Por tales motivos persistían numerosos abusos y supersticiones, de los que el Sínodo de 1591 en algunas ocasiones se hace eco: se exhorta a los fieles a guardar el respeto debido en la celebración de los divinos oficios ${ }^{77}$, se denuncia a quienes "usan adivinanzas, hechicerías y encantamientos", prohibiéndose que "saludadores ni ensalmadores" ejercieran su perniciosa acción, así como las "oraciones con ritos y ceremonias supersticiosas" ${ }^{78}$, se denuncia la frecuencia de la blasfemia ${ }^{79}$, se prohíbe la práctica de la usura ${ }^{80}$ y se exhorta a los visitadores a publicar anualmente un edicto general de visita cuyo contenido nos muestra a grandes rasgos las principales preocupaciones de la jerarquía eclesiástica ${ }^{81}$.

\section{LOS OBISPOS Y SU ACCIÓN}

A mediados del siglo xvi había mucho por hacer en la diócesis gadicense. La acción de reconquista espiritual será realizada en un primer momento por las órdenes religiosas, siendo el principal arbitrio empleado por las mismas la organización de misiones, tarea en la que jugó un papel muy importante la Compañía de Jesús: ya en 1557 enviaron dos hermanos legos a las almadrabas de Conil y Zahara que lograron colocar imágenes

${ }_{77}$ Ibidem, tit. VI.

78 Ibidem, tit. XXIII, pág. 1.

79 lbidem, tit. XXIII, pág. 6.

so Ibidem, tit. XXIV.

B1 "Algunas personas... cometen otros pecados abominables y escandalosos, como son el usar de hechicerías, encantamientos, agueros, suertes o adivinanzas, y hacer ligaduras de hombres y mujeres, y tomar consejo con los que hacen los tales maleficios (que son siervos del demonio)... y hay personas que ensalman de mal de ojo, con palabras supersticiosas, cortando el bazo y la rosa, encomendando los ganados, y otras cosas perdidas, y tiene libros de conjuros, supersticiosos y nóminas reprobadas, y otros que son usureros y logreros, y venden trigo, y otras cosas fiadas... y que algunas personas han dicho palabras de blasfemia contra Dios Nuestro Señor y su bendita Madre y sus gloriosos santos... o que tratan deshonestamente con parientas suyas o de sus mujeres... y otros que están casados dos veces... y que hay algunos casados que están apartados por su propia autoridad y no hacen vida maridable... y otros que están desposados y hacen vida maridable... sin haber recibido las bendiciones nupciales. $Y$ asi mismo hay muchos amancebados, solteros y casados con mujeres solteras, viudas y casadas, teniéndolas en sus casas, o saliendo y entrando en las de ellas con publicidad y escándalo, y que hay señores que permiten a sus criados y esclavos estar amancebados públicamente, y muchos que no oyen misa entera, los domingos y fiestas de la lglesia, ni guardan las dichas fiestas, haciendo obras serviles... y otros que inducidamente se han dejado estar y perseverar en sentencia de excomunión mucho tiempo... item que algunos han puesto las manos injuriosamente, en personas eclesiásticas, y han cometido sacrilegios y delitos, en iglesias y cementerios, y sacado de ellos violentamente algunas personas... y que han profanado los tales lugares con juegos, comidas, representaciones y otras cosas indecentes y prohibidas" (Ibidem, tit. XXX, pág. 28). 
de santos en las chozas de los pescadores y pretendieron erradicar los juramentos y las blasfemias. Al año siguiente Diego López y Gregorio de Mata enseñaron la doctrina cristiana, administraron el sacramento de la confesión y clausuraron el burdel existente. En 1582 y 1599 misionaría en esta zona el padre Pedro de León ${ }^{82}$ que ejercería su acción evangelizadora conviviendo estrechamente con los pescadores, participando en sus labores y presentándose en las tabernas a la caída de la tarde. Su interés principal era ganarse la confianza de estas gentes y a partir de ahí instruirles en la doctrina cristiana, parece ser que con buenos resultados ${ }^{83}$.

Durante gran parte del siglo xvı los obispos gaditanos constituyeron una fuerza con la que no se pudo contar a la hora de ejercer esta acción de reforma de las costumbres, no por una especial mala voluntad, sino, sencillamente, porque no se encontraban entre sus ovejas. El 6 de septiembre de 1525 era nombrado como prelado de la sede gaditana Jerónimo de Teodoli, que si bien apoyó la fundación de algunos conventos en el obispado (como el de franciscanas concepcionistas de Santa María sito en la urbe gaditana), centró sus preocupaciones en los pleitos mantenidos con la Universidad de Beneficiados de Jerez de la Frontera acerca de la cobranza de los diezmos, ausentándose del obispado desde 1547 , año en que asistía al concilio de Trento, dejando el gobierno de la diócesis a cargo de provisores y vicarios generales. En 1565, empero, permutaba el obispado por ciertos beneficios situados en Sicilia gozados por un tal García de Haro y Sotomayor, hijo de los señores del Carpio ${ }^{84}$. A partir de este momento, la situación iba a cambiar.

García de Haro (1565-1587), de hecho, supone el inicio de la Reforma católica en la diócesis de Cádiz. Con él llegaba a nuestro obispado un prelado de nuevo cuño, interesado ante todo por el servicio a las ovejas a su cargo y el cuidado por procurar un cuerpo pastoral consciente de sus deberes. Pero su principal preocupación a corto plazo fue devolver a la dignidad episcopal todos los derechos perdidos durante la larga ausencia de Jerónimo de Teodoli y de los obispos de origen italiano que precedieron a éste, privilegios que habían sido usurpados por un cabildo catedralicio que se había vuelto muy celoso de su autonomía y que se había acostumbrado a no rendir cuentas a ninguna autoridad superior.

82 ANTÓN SOLÉ, P., Los pícaros de Conil y Zahara. Estudio histórico sobre los jesuitas y las almadrabas del duque de Medina Sidonia en la segunda mitad del siglo xvı. Cádiz 1965, pág. 44ss. 350.

Herrera Puga, F., Sociedad y delincuencia en el Siglo de Oro. Madrid 1974, págs. 349-

84 Gerónimo de la Concepción, op. cit., págs. 547-548. 
De esta manera, García de Haro pleiteó incesantemente con el capítulo gaditano por la administración de las rentas decimales y la fábrica de la catedral y por el nombramiento de los capellanes de coro, y con el ayuntamiento gadicense por el privilegio esgrimido por éste de que las raciones fueran provistas en naturales de la ciudad, aunque en este caso sin éxito. Lo cierto es que, aunque García de Haro no triunfara en sus pretensiones, consiguió que el cabildo catedralicio se endeudara por los gastos ocasionados por todos estos pleitos hasta tal punto que se vio obligado a imponer un censo de 4.000 ducados sobre los bienes de la mesa capitular. Nuestro prelado se ocuparía también de construir una nueva sala capitular en la Iglesia de Santa Cruz, lo que tuvo lugar en 1572, y, ya una vez trasladado a Málaga, donó en 15978.000 ducados para proceder a la reedificación de dicho templo ${ }^{85}$. Desde un punto de vista más positivo, Garcia de Haro jugó un destacado papel en la implantación de nuevos institutos monásticos en la diócesis, debiéndose a su acción el surgimiento de los conventos de Nuestra Señora de la Candelaria y de los franciscanos observantes, ambos en la urbe gaditana ${ }^{86}$.

Su sucesor sería Antonio Zapata y Cisneros (1587-1596) primogénito del conde de Barajas y antiguo inquisidor, racionero y canónigo en las sedes de Cuenca y Toledo. A diferencia de Haro, deseó resolver las diferencias tenidas con el cabildo gaditano, para la cual en 1593 firmaba una concordia con el mismo que sería confirmada por el papa Clemente VIII en la bula Pastoralis Officij promulgada tres años más tarde, en la cual se resolvía, entre otras cosas, que la administración de las rentas decimales tocaría al capítulo, al igual que la de los bienes de la fábrica de la Iglesia de Santa Cruz, y que al cabildo pertenecía la provisión de las capellanías de coro ${ }^{87}$, lo que en el fondo suponía una flagrante derrota de las pretensiones de los prelados.

Nos da la impresión, empero, que Zapata prefirió tener las manos libres de pleitos con el capítuo para emprender su tarea reformadora. El 21 de febrero de 1591, de hecho, promulgaba un edicto dirigido a todos los eclesiásticos del obispado y a los señores temporales de las ciudades, villas y lugares del mismo, en el cual, en conformidad con los decretos conciliares, procedía a la convocatoria de un sínodo diocesano, a fin de

«proveer lo que convenga en la reformación de la vida y costumbres de nuestros súbditos diocesanos, bien y utilidad de las iglesias, aumento

85 Ibidem, págs. 548-550.

36 Ibidem, pág. 617, y SanCHO de Sopranis, H. Op. cit.

${ }^{87} \mathrm{ADC}$, Erección de la Santa Iglesia..., "Concordia inter ilustrissimos ac reverendissimos Dominos Episcopos et lllustrissimos Dominos Decanum et Capitulum... ann. 1593". 
del culto divino, conservación y reformación de los bienes y rentas de las fábricas y finalmente para corrección y enmienda de los excesos, abusos y malas costumbres",

exhortando a que dos representantes del cabildo catedralicio y el vicario y el cura más antiguo de cada parroquia de la diócesis se presentaran el 7 de marzo para proceder a la inauguración de la asamblea sinodal ${ }^{88}$.

El sínodo de 1591 debió contar con un número de asistentes relativamente elevado, tal como consta de la relación de testigos sinodales presentes el 12 de marzo de 1591, fecha en que se aprobaron las constituciones: un total de 24, el chantre Diego de Mendoza, el canónigo Hernán Ramírez de Cartagena y dos clérigos por cáda una de las localidades del obispado (exceptuando Paterna y Castellar que solamente enviaron a uno), normalmente los vicarios 0 los curas ${ }^{89}$. Nos consta además que ciertos sectores del estamento eclesiástico enviaron una serie de peticiones previas donde constaban aquellas cuestiones de particular gravedad: el clero de Chiclana solicitaba, entre otras cosas, que los religiosos no pidieran limosna sin licencia episcopal, que hubiera una tasa mínima de las misas de capellanías y testamentos, que ningún clérigo fuese vestido de sobrepelliz a carnicería y pescadería, que el sacristán menor no estuviera casado a fin de no obstarle ello al servicio de la Iglesia, que los eclesiásticos no se dedicaran a cazar con escopeta, que los domingos y festivos solamente se dijera cantada la misa mayor, y que curas y capellanes no estuvieran obligados a rezar los maitines ${ }^{90}$. Por su parte, el 14 de marzo de 1590, el deán del cabildo gaditano Rodrigo de Villavicencio planteaba en nombre del cuerpo capitular la asignación de una dote mínima a las fundaciones de aniversarios a fin de descargar a los prebendados de unas obligaciones muy gravosas que tan escasos beneficios económicos reportaban, lamentándose además por las cargas e imposiciones que pesaban sobre los clérigos ${ }^{91}$.

La segunda gran iniciativa de Zapata sería la fundación del seminario conciliar de San Bartolomé, movido por la escasez de centros de estudio existentes en el obispado, puesto que era el colegio de Santiago de la Compañía de Jesús sito en Cádiz la única institución que desempeñaba estas tareas: tal como indicaba el prelado en las Constituciones de 1596

ADC, Secretaría, leg. 1 , doc. 4

"Constituciones antiguas", tit. XXXII, pág. 3.

90 ADC, Secretaría, leg. 1, doc. 4.

91 lbidem. 
"en este obispado no hay colegio ni estudio fuera de esta ciudad y que por estar las universidades muy distantes dél y ser la gente que de ordinario al servicio de las iglesias se dedica, pobre, y los premios cortos, son muy pocos los que estudian más de los preciso para poderse ordenar, de que resultan grandes inconvenientes". Desde el primer momento contaria Zapata con el apoyo del cabildo gaditano, y el 14 de julio de 1589 se reunian al efecto nuestro obispo, el canónigo Álvaro Arias, el deán Rodrigo de Villavicencio, el cura de la catedral Juan de Luna y el cura Domingo Ruiz en nombre de los párrocos de la diócesis, acordando la erección del seminario gaditano bajo la advocación de San Bartolomé, que se recibieran en el mismo veinte colegiales pobres y naturales del obispado, y que sus ingresos fuesen proporcionados por las rentas de once beneficios simples existentes en la diócesis, ninguno de los cuales llevaba aneja la obligación de cura de almas. El 28 de agosto se nombraba como primer rector al racionero Martín de Haya y el 2 de noviembre ingresaban los primeros colegiales, remitiéndose en 1592 a la Sagrada Congregación del Concilio el expediente de erección (la cual fue aprobada por ésta al ajustarse a las disposiciones tridentinas) y promulgándose en 1596 las primeras constituciones, muy influidas por las del colegio de San Bartolomé de Salamanca, en el cual había cursado sus estudios nuestro prelado ${ }^{92}$.

La acción de Zapata, a diferencia de las actuaciones de su predecesor, estuvo marcada en todo momento por el signo de la conciliación: comprendió que nada se ganaba actuando en contra de los intereses del cabildo catedralicio y que era mucho más acertado vincularlo estrechamente a la ejecución de sus acciones reformadoras. Cuando el 13 de mayo de 1596 era promovido a la sede de Pamplona, desarrollando con posterioridad una destacada carrera que le llevaría al cargo de Inquisidor General, la diócesis perdió uno de los mejores obispos que tuvo a lo largo de toda su existencia.

Maximiliano de Austria (1596-1602), primo de Felipe II, será el último prelado del siglo XVI gaditano. Ya no encontraremos en él grandes iniciativas, puesto que la ciudad había sufrido mucho tras el asalto inglés de 1596, y sus principales preocupaciones serían la reconstrucción de la Iglesia de Santa Cruz, el rescate de los rehenes tomados por los ingleses y conseguir que el cabildo regresara de Medina Sidonia, localidad en la cual, con el apoyo del duque, pretendían permanecer a perpetuidad so

92 Morgado Garcia, A., "Los alumnos del Seminario de San Bartolomé (1589-1849)", Gades, 18, 1988. 
pretexto de la expuesta situación de la urbe gaditana a las incursiones de los enemigos de la corona española. En 1602 sería promovido al obispado de Segovia y con posterioridad al arzobispado de Santiago de Compostela, donde fallecía doce años más tarde ${ }^{93}$. Sería sucedido por una serie de prelados de los que sabemos muy poco y que no mostraron grandes iniciativas, entre otras razones porque casi todos ellos permanecieron muy pocos años en la diócesis. Solamente a finales del siglo XVII volveremos a encontrar nuevos síntomas de renovación. Pero, por aquel entonces, ya Cádiz no era la capital de una diócesis pequeña, pobre y marginal, sino el «Emporio del Orbe». Ello significaba nuevas oportunidades, nuevas perspectivas y nuevos problemas a los que los prelados del finales del Seiscientos y del XVIII tendrian que hacer frente. Pero ello, como diría Kipling, ya es otra historia.

93 Gerónimo de la Concepción, op. cit., págs. 552, 565-567. 